\title{
Price-related consumer discussions in China and the United States: a cross-cultural study investigating price perceptions and word-of-mouth transmission
}

\author{
Sebastian Schneider ${ }^{1}$
}

Received: 22 April 2021 / Accepted: 30 May 2021 / Published online: 23 June 2021

(c) The Author(s) 2021

\begin{abstract}
Prices are among the most frequently discussed topics in consumer research. Although word-of-mouth is known to be highly influential and it is considered to be of growing importance, previous research has largely neglected price-related wordof-mouth, especially in a cross-cultural context. The present study fills this research gap by analyzing the effects of pricerelated word-of-mouth valence, price changes communicated by word-of-mouth, market mavenism and national culture on price fairness and expensiveness perceptions, as well as on subsequent word-of-mouth intentions. Two studies employing Hofstede's national culture dimensions reveal considerable differences between the cultures of the United States and China.
\end{abstract}

Keywords Pricing · Word-of-mouth · Price perception · Transmission · Cross-cultural comparison

\section{Introduction}

Product prices are the most frequently discussed topic in conversations between friends and acquaintances about vendors or service providers (Lexis et al. 2013). As wordof-mouth (WOM) is a highly influential market force and marketing scholars agree that it will become even more relevant in the future, it is crucial to understand the impact of price-related WOM on consumer behavior (Allsopp et al. 2007; Bansal and Voyer 2000; Kozinets et al. 2010; Siems and Gerstandl 2011; Zhu and Zhang 2010). Past research has found that WOM is highly persuasive, is extremely effective, and often has a greater influence on consumer behavior than traditional marketing tools (Bone 1995; Bristor 1990; Engel et al. 1969; Goldsmith and Horowitz 2006; Hennig-Thurau and Walsh 2004; Herr et al. 1991; Katz and Lazarsfeld 1955; Zhang et al. 2018). The effect of WOM has been found to be 30 times higher than the impact of media messaging, and its elasticity is 20 times higher than that of marketing events (Trusov et al. 2009). As 20 to 50\% of purchasing

Sebastian Schneider

schneider@marketing-mainz.de

1 Department of Law and Economics, Chair of Marketing Analytics, Johannes Gutenberg University, Jakob Welder-Weg 9, 55128 Mainz, Germany decisions are primarily made due to WOM, managers will inevitably take WOM into account in their marketing plans (Breazeale 2009; Bughin et al. 2010; Radighieri and Mulder 2014; Wicken and Asquith 2008).

Although prices play a dominant role in consumer discussions and manifold studies have attested to WOM's massive influence on consumer behavior, the research on pricerelated WOM is sparse. The very few studies that combine the topics of behavioral pricing and WOM have focused on situations that encourage the initiation of WOM with regard to prices; however, they have failed to explore possible knock-on effects and WOM diffusion (Lexis et al. 2013; Siems and Gerstandl 2011). This lack of research leaves marketing practitioners in the dark in terms of how to utilize this potentially highly influential process, which exhibits strong potential as a marketing tool for influencing consumer price perceptions in a self-reinforcing process (Siems and Gerstandl 2011). The fact that consumers perceive WOM as credible, trustworthy, and accessible and that firms are already using it to grow their customer base, stimulate purchasing behavior, and gain advantages over their competitors highlights the urgency of the need to obtain insights into price WOM as one of the most common forms of WOM (Brown and Reingen 1987; Chevalier and Mayzlin 2006; Hervas-Drane 2015; Lexis et al. 2013; Liu 2006; Murray 1991). Price-WOM differs significantly from other forms of WOM as price functions as a signal of quality in situations in 
which companies possess more information than consumers about product quality (Bagwell and Riordan 1991; Milgrom and Roberts 1986). Therefore, prices have a unique signaling role within WOM (Guadalupi 2018).

While WOM has been found in many cultures, the prior research has not yet comprehensively clarified whether the use of WOM is influenced by culture (Abratt et al. 1995; Christiansen and Tax 2000; Christiansen and Tsiourtis 1998). Christiansen and Tax (2000) assume that culture might affect the degree of WOM activity or the social circumstances involved in WOM diffusion. Similarly, the way in which cultural factors influence price perceptions is not yet well understood (Lalwani and Forcum 2016). This lack of research leaves decision-makers in the dark about global differences with regard to how they might best employ pricerelated WOM to influence consumers' price perceptions, a question that is particularly crucial in times of increased corporate and consumer communications (Allsopp et al. 2007; Kozinets et al. 2010; Siems and Gerstandl 2011; Zhu and Zhang 2010). Firms currently face a high level of uncertainty concerning the dissemination of price information and its outcomes in different cultures. It is not yet possible for managers to develop country-specific price-related WOM strategies. Consequently, a cross-cultural study of pricerelated WOM that addresses the aforementioned research gaps and that meets the general call for more country-specific studies on consumer behavior is urgently needed (Frank et al. 2014).

Although the ability to engage in WOM via online channels has led to an increased amount of WOM, studies have indicated that prices tend to be discussed more frequently offline and that offline WOM leads to stronger consumer reactions (Baker et al. 2016; Goles et al. 2009; Packard et al. 2016; Siems and Gerstandl 2011). Furthermore, face-to-face WOM is more persuasive than any print form of WOM, and consumers generally prefer personal communication in an offline environment (Herr et al. 1991; Lexis et al. 2013). Hence, the present study considers price-related WOM in an offline situation to shed more light on this under-studied research topic.

The existing literature emphasizes the important role of market mavens for the diffusion of WOM as they have an elevated baseline transmission (Slama et al. 2015; Stephen and Lehmann 2009). Feick and Price (1987) define market mavens as "individuals who have information about many kinds of products, places to shop, and other facets of markets, and initiate discussions with consumers and respond to requests from consumers for market information". As market mavens are usually among the first to transmit messages and share their broad knowledge in many different categories with others, they may also play an important role in pricerelated WOM (Goodey and East 2008; Kaplan and Haenlein 2011). Goodey and East (2008) suspect that mavenism differs depending on national culture. Drawing upon these findings, the present study considers the concept of market mavenism to evaluate its importance for updated price perceptions due to WOM.

To address the aforementioned research gaps, the current study provides insights into the process of price-related WOM. It is the first cross-cultural study to explore the effects of incoming price-related $\mathrm{WOM}^{1}$ on price perceptions and subsequent WOM intentions. The author set the content of the WOM message as either positive or negative price evaluations by the WOM transmitter as well as information about a recent price change discussed in a face-to-face conversation. Consequently, the study provides two insights: First, it examines the role of culture in terms of how price-related WOM influences perceived price fairness and expensiveness. It is important for both researchers and international managers to learn in which cultures WOM transmitters' opinions and the communication of a price change via WOM have a stronger influence on individuals' price perceptions. Thus, the present study also explores the impact of market mavens of different cultural backgrounds on price perceptions. Second, the study makes a first attempt to understand price-related WOM diffusion in a cross-cultural comparison to analyze in which culture(s) conversations about price changes lead to higher positive and negative WOM intentions. Specifically, it focuses on the cultural traits that influence the effects of the opinion of a WOM transmitter on the receiver's subsequent positive or negative WOM intentions.

Hofstede's (1980) national culture dimensions are used as the theoretical framework informing the study as they are one of the most common operationalizations of culture in the marketing literature (Sivakumar 2014; Søndergaard 1994). Since past research has shown that the United States (US) and China score very differently on many of Hofstede's cultural dimensions, this study examines those two cultures to compare and contrast a Western culture and an Eastern culture (Bolton et al. 2010; Lee 2000; Markus and Kitayama 1991).

\section{Theoretical background, hypotheses, and conceptual framework}

\section{Hofstede's national culture dimensions}

The present study draws from Hofstede's cultural dimensions framework, which measures culture through distinct values (Hofstede 1983, 2001). Because culture influences national institutions, it also affects exchanges among

\footnotetext{
1 WOM can be both a precursor and an outcome of individual actions (Godes \& Mayzlin, 2004).
} 
individuals, making it suitable for WOM research (Hofstede 1983). Furthermore, it is a relevant cultural framework for understanding consumers' fairness perceptions, which have not yet been fully explored in the pricing context (Lund et al. 2013).

Individualism is the most frequently examined of Hofstede's national culture dimensions in consumer behavior and psychology (Frank et al. 2015; Soares et al. 2007; Taras et al. 2010). The opposite of individualism is collectivism, and the distinction between the two refers to the relative importance of the individual versus the group in a given culture (Moon and Franke 2000). The current study also focuses on the individualism dimension by applying it in the majority of research hypotheses; however, it does not omit Hofstede's other cultural dimensions. Hofstede (1980) defines uncertainty avoidance as "the extent to which a culture tolerates ambiguity and uncertainty" (Hood and Logsdon 2002). In weak uncertainty avoidance cultures, individuals are more secure while strong uncertainty avoidance societies exhibit a high amount of anxiety (Tsui and Windsor 2001). High masculinity nations expect strong differences in gender roles, with men perceived as "assertive, tough, focused on material success, etc., while women are supposed to be tender, concerned with quality of life, etc." (Christie et al. 2003). Power distance refers to the acceptance of inequality within a society. Whereas people accept an unequal distribution of power in large power distance countries, individuals in low power distance countries value an equal distribution of power (Tsui and Windsor 2001). In cultures exhibiting a long-term orientation, people prioritize values that are important for the future while in societies with a short-term orientation, individuals emphasize values related to the past and the present (Christie et al. 2003). The indulgence dimension is not applied in the present research because the other dimensions are much more relevant for the topic.

\section{Cultural differences in price perceptions resulting from the opinion of a WOM transmitter}

Since this study considers consumer price perceptions related to fairness and expensiveness, it is important to clarify that expensiveness is a more basic consumer price perception because it involves the direct consideration of a product's price whereas price fairness includes judgments about whether a price is just, legitimate, and reasonable (Campbell 2007; Haws and Bearden 2006; Kwak et al. 2015). The dual entitlement principle is often used to estimate price fairness perceptions (Campbell 1999; Homburg et al. 2005). The central tenet of this principle is that consumers are entitled to a fair price while companies are entitled to a certain profit, and prices will be perceived as unfair when this relationship is unbalanced in favor of the company (Kwak et al. 2015). A WOM transmitter's negative opinion about a price is likely to lead the receiver to evaluate the relationship between the company and the consumer as unbalanced. Thus, in line with the dual entitlement principle, negatively valanced price-related WOM should lead to lower perceived price fairness.

The P-O-X model can facilitate a deeper understanding of changed expensiveness perceptions due to WOM (Hummon and Doreian 2003). This model posits that individuals prefer a balanced relationship between two persons and an object. Whenever an imbalance occurs, consumers are exposed to cognitive dissonance and resolve it by adjusting their own attitude towards the object (Heider 1946). When a consumer receives a positively or negatively valanced price-related message via WOM, he or she can resolve the resulting cognitive dissonance by adapting his or her perception of the product's expensiveness to match the transmitter's opinion.

In addition to the potential direct effects that result from the dual entitlement principle and the P-O-X model, Hofstede's cultural dimensions may also play a role here. Collectivists are highly interested in the well-being of their in-group (Lee 2000). They strive for harmony within their in-group and adjust their opinions to match those of in-group members; their opinions thus also tend to differ from those of out-group members (Bolton et al. 2010; Pickett and Brewer 2001; Ryu and Han 2009). However, in-groups have been found to include only a very small number of persons (Rhee et al. 1996). Put differently, collectivists care far less about the majority of people with whom they might engage in a WOM conversation, and the effect of in-groups on decisions has recently been found to be strong only when there is a large share of in-group members (Van Parys \& Ash 2018). Individualists, who do not follow in-group principles, might be equally open to WOM from a wide range of people. Thus, across the entire spectrum of people that might be involved in a WOM conversation, individualists might tend to react more strongly to the WOM transmitter's positive or negative opinion of a product. Previous work by Bolton et al. (2010) supports this notion in the pricing context. They found that collectivists are concerned only about losing "face", in the sense of social status, within their in-group, whereas individualists are equally concerned in response to all conversation partners when discussing prices (Ho 1976). Furthermore, individualists are more interested in actualizing their internal self and value intellectual property such as knowledge compared to in-group collectivists who tend to care more about interpersonal harmony (Budde-Sung 2013; Heine et al. 1999). This notion could mean that price-related WOM is more easily able to adjust individualists' internal price perceptions. Similarly, individuals in collectivist cultures assign only a secondary role to the opinions of others, which should mean that the opinion of a WOM transmitter has less strong of an impact in such cultures than in 
individualist societies (Markus and Kitayama 1991). Findings that individualism has a stronger moderating effect for services compared to products makes these considerations even more relevant for the current study, which focuses on a media service (Frank et al. 2015).

Turning to a second cultural dimension, the recent research has shown that high uncertainty avoidance cultures place high importance on fairness perceptions (Lund et al. 2013). For the current study, this tendency could lead to a stronger effect of price-related WOM valence on price fairness perceptions in high uncertainty avoidance cultures. Such cultures may be highly interested in any and all available information when forming their price fairness judgments; therefore, they might closely consider information received via WOM.

Dwyer et al. (2005) found that short-term oriented cultures have a higher product diffusion rate. They explain this finding with reference to the more materialistic values of short-term oriented societies. Such individuals also require corresponding expensiveness perceptions, which lead to high purchase intentions and in turn fuel high diffusion rates (Huettl and Gierl 2012). It can be expected that short-term oriented consumers' expensiveness perceptions are more easily influenced by price-related WOM compared to long-term oriented consumers. From another perspective, price-related WOM could be a driver of strong changes in short-term oriented consumers' expensiveness perceptions while simultaneously arousing their interest in products that are perceived as inexpensive, leading to a high diffusion rate. Individualists' generally higher brand purchasing behavior supports this notion for the individualism cultural dimension as brand purchasing behavior requires a corresponding expensiveness perception (Huettl and Gierl 2012; Zhang and Nelson 2016). Furthermore, individualist cultures are known to consider resources to a lesser extent than collectivist cultures (Lee 2000). This difference might mean that expensiveness perceptions in individualist cultures are more easily influenced by the opinion of a price-related WOM transmitter as individualists do not consider their level of personal resources to the same extent that collectivists do. Hence, the following hypotheses can be derived based on Hofstede's cultural dimensions of individualism, uncertainty avoidance and long-term orientation:

H1 Individualism/uncertainty avoidance strengthens the negative effect of negative price-related WOM on perceived price fairness.

H2 Positive price-related WOM reduces perceptions of price expensiveness, and this effect is stronger in individualist/ short-term oriented cultures.
Cultural differences in perceived expensiveness due to word-of-mouth information about a price change

In contrast to the research on price reductions, studies concerning price increases are very scarce (Homburg et al. 2010). The present study fills this research gap by considering price increases as well as reductions. To further advance the research on this topic, the author examines consumers from different cultures who learn about a price change via WOM. Past studies have shown that reductions in individuals' budgets due to price increases lead to changes in purchasing behavior (Du and Kamakura 2008; Homburg et al. 2010). As perceived expensiveness has a strong impact on consumers' buying behavior, it can be assumed that such behavioral changes are due, inter alia, to higher perceived expensiveness (Huettl and Gierl 2012).

Price increases are more readily accepted in high power distance countries than in low power distance countries (Maxwell 1999). This effect can be expected to hold for price increases communicated via WOM. Accordingly, individuals from high power distance cultures should not adjust their expensiveness perceptions in response to price increases communicated via WOM to the same extent as individuals from low power distance cultures. This assumption is supported by the fact that people from high power distance cultures accept that the market consists of different price levels (Sivakumar 2014). A similar effect can be expected for collectivist cultures, which tend to believe that sellers adhere to social norms while individualists tend to be rather critical of sellers' actions (Maxwell 1999). Consequently, collectivists should not adjust their expensiveness perceptions as strongly as individualists after hearing about a price increase. Supporting this assumption, Sivakumar (2014) found that collectivists react less strongly to price changes because they employ a different price reference system than that employed by individualists. Furthermore, Kwak et al. (2015) found that individualist cultures' self-focus leads to stronger reactions to price increases than in collectivist cultures, which might also apply to price increases communicated via WOM. Similarly, strong changes in perceived expensiveness can be assumed for high uncertainty avoidance cultures as such cultures exhibit a high loss aversion (Kahneman and Tversky 1979; Sivakumar 2014). With respect to long-term orientation, it has been postulated that individuals in long-term oriented cultures maintain a price history and evaluate prices according to a fixed reference price that changes much less frequently than that of individuals in short-term oriented societies (Sivakumar 2014). This postulate could mean that long-term oriented cultures tend to stick to their long-term individual price histories rather than drastically adjusting their price expensiveness perceptions after a price change has been communicated via WOM. Hence, in line with insights concerning Hofstede's 
cultural dimensions of power distance, individualism, longterm orientation, and uncertainty avoidance, the following hypothesis can be postulated:

H3 Power distance/collectivism/long-term orientation weakens while uncertainty avoidance strengthens the positive effect of a price increase communicated by WOM on perceived price expensiveness.

\section{Cross-cultural comparison of the role of market mavenism for price expensiveness perceptions}

Addressing Goodey and East (2008) criticism of the lack of cross-cultural studies on market mavenism, the present study considers this construct with respect to price expensiveness perceptions. Market mavens are not defined as early adopters per se; however, they exhibit an early awareness of products, which in turn leads to early adoption and indicates a strong relevance for expensiveness perception as a possible driver of buying behavior (Feick and Price 1987; Huettl and Gierl 2012). This desire to adopt and purchase products at an early stage ought to be accompanied by mavens perceiving new products as inexpensive (Huettl and Gierl 2012). A study of the French media services market found evidence of such behavior for internet access, which is the current study's research subject (Fornerino, 2003). However, as opposed to the case of new products, which market mavens tend to perceive as inexpensive, this service is no longer at an early stage, leading to market mavens perceiving it as expensive.

Past research has found the cultural dimension of masculinity to positively influence consumer innovativeness (Dwyer et al. 2005; Steenkamp et al. 1999). As innovators have a propensity to adopt new products, the previously introduced effect of market mavenism on perceived expensiveness should be especially strong for innovators (Hirschman 1980; Rogers 1983). Consequently, masculinity, as a cultural dimension that positively influences consumer innovativeness, should strengthen the effect of market mavenism on perceived price expensiveness (Steenkamp et al. 1999). Furthermore, it is known that masculine cultures focus more strongly on a product's price in regard to decision-making (Sivakumar 2014). Thus, it can be assumed that such societies closely inspect prices, which should strengthen the market mavenism effect and further underpin the assumption concerning the impact of innovativeness in masculine countries.

The dimension of power distance has been found to positively influence the diffusion of innovative products because powerful individuals use new products to demonstrate their status and influence other members of society (Dwyer et al. 2005). Therefore, power distance can be assumed to exhibit the same effect as masculinity.
As uncertainty avoidance is known to have a negative influence on consumer innovativeness, it should weaken rather than strengthen the effect of mavenism on perceived expensiveness (Steenkamp et al. 1999). Consequently, the author formulated the following hypothesis:

H4 Masculinity/power distance strengthens, while uncertainty avoidance weakens, the positive effect of market mavenism on perceived price expensiveness.

\section{Cross-cultural comparison of positive and negative word-of-mouth in response to exposure to consumer discussions about a price change}

Prospect theory is quite applicable to the pricing context, especially when evaluating reactions to price changes (Marshall and $\mathrm{Na} 2000$ ). It identifies consumer processes that are perceived as gains or losses, employs a function that relates actual values to psychological values, and shows that value losses lead to negative feelings while value gains lead to positive sentiments (Kahneman and Tversky 1979). Subsequently, these negative and positive feelings lead individuals to spread negative and positive opinions via WOM (Anderson 1998; Goldenberg et al. 2001). Furthermore, Lexis et al. (2013) demonstrated that price changes affect the intention to spread information via WOM. It can be assumed that these relationships apply not only to actual, visible price changes but also to price changes communicated via WOM. Based on prospect theory, a price reduction communicated in a consumer discussion should lead to higher positive WOM intention compared to a price increase while a price increase should lead to higher negative WOM intention compared to a price reduction.

Marshall and $\mathrm{Na}$ (2000) found that consumers in the US, which is an individualist Western culture, notice price reductions to a far greater extent than citizens of Singapore, which is a collectivist Eastern culture. This finding suggests a higher overall sensitivity to price changes in individualist cultures. It can be assumed that it also applies to price changes communicated through consumer discussions, leading to a stronger subsequent reaction in the form of WOM. Additionally, individualists are better able to withstand the influence of external forces such as social interactions (Frank et al. 2015). For the current study, this tendency could mean that individualists exhibit stronger reactions to price changes in terms of subsequent WOM intentions to overcome potential obstinance on the part of their individualist conversation partners. Similarly, the finding that individualists perceive price increases by humanized brands more unfairly than collectivists underpins the assumption that price changes will have a stronger effect on subsequent WOM in individualist cultures (Kwak et al. 2015). As high power distance cultures more readily accept that sellers are able to set prices, it can 
be argued that they will not see a need to spread positive or negative opinions through WOM in response to a price change (Maxwell 1999). Thus, low power distance cultures might exhibit a stronger effect of price changes on positive/ negative WOM intentions. It is known that feminine cultures exhibit higher ethical sensitivity compared to masculine cultures (Moon and Franke 2000). This tendency could mean that feminine cultures feel a stronger obligation to spread corresponding WOM after hearing about a price change to meet their moral standards. In this case, femininity might strengthen the effect of a price change on subsequent WOM intentions. Hence, following prospect theory and Hofstede's cultural dimensions, the author postulates the following hypothesis:

H5a Individualism/low power distance/femininity strengthen(s) the negative effect of a price increase communicated between consumers on positive WOM intentions.

H5b Individualism/low power distance/femininity strengthen(s) the positive effect of a price increase communicated between consumers on negative WOM intentions.

\section{Cross-cultural comparison of the effects of a WOM transmitter's positive and negative opinion about a price on subsequent WOM behavior}

In the literature, the positivity or negativity of a WOM message is described as its valence (Baker et al. 2016). Positive WOM generally leads to brand purchase intentions and positive consumer behavior while negative WOM leads to decreased purchase intentions and reduced interactions with the brand (Bansal and Voyer 2000; Ryu and Feick 2007). While the literature has not yet fully explored price-related WOM dissemination, this study draws upon the brandrelated research to postulate that receiving positively valanced price-related WOM, in the sense of a positive pricerelated opinion of the WOM transmitter, ought to lead the receiver to exhibit positive WOM intentions while receiving negative WOM, in the sense of a negative price-related opinion of the WOM transmitter, should lead to negative WOM intentions (Radighieri and Mulder 2014). This assumption is substantiated by the accessibility-diagnosticity model, which assesses the likelihood of a cognition being used as an input for a judgment or specific behavior (Feldman and Lynch 1988; Lynch 2006). This model states that the likelihood of considering information is a function of the accessibility of the input, the accessibility of alternative inputs, and the diagnosticities of the input as well as possible alternatives. As consumers evaluate price information as generally diagnostic, receiving price information can lead to retrieval cues. In such situations, the anticipated diagnosticity leads to higher accessibility (Lynch et al. 1988). Face-to-face WOM is extremely accessible due to its vividness (Herr et al. 1991). Its credibility and trustworthiness lead to a feeling of high diagnosticity (Bone 1995). In turn, this high degree of both accessibility and diagnosticity helps individuals make judgments and should in turn lead to corresponding positively or negatively valanced WOM intentions (Radighieri and Mulder 2014).

As mentioned above, individualists are better able to withstand influences by external forces (Frank et al. 2015). This tendency suggests a fundamental position-involved attitude among individuals from such cultures. Positioninvolved consumers have been found to support positive information more than negative information (Ahluwalia 2002). For the current study, this support might suggest a stronger overall impact of WOM valence on subsequent positive WOM intentions among individualists compared to collectivists who might in turn exhibit stronger negative WOM intentions. Supporting this assertion, collectivists' concern about "face" means that they could lose social status if they pay a price that is negatively perceived, making negative price information more vital than positive price information (Bolton et al. 2010). Consequently, negatively valanced WOM transmission might play a more important role in collectivist cultures as a way of warning others and preventing them from losing "face". Such behaviors allow members of collectivist societies to act in accordance with the expectations of others and with other individuals' concern for them (Markus and Kitayama 1991; Yang 1981). However, in individualist societies, it is important to demonstrate one's superior position as part of a status game. This demonstration could strengthen the effect of WOM valence on positive WOM intentions as knowledge about positive circumstances might serve to highlight one's success and thus improve one's status (Patsiaouras and Fitchett 2012; Zhang and Nelson 2016). Hence, the following hypotheses can be postulated on the basis of these differences between individualist and collectivist cultures:

H6a Individualism strengthens the positive effect of receiving positively valanced price-related WOM on positive WOM intentions.

H6b Collectivism strengthens the positive effect of receiving negatively valanced price-related WOM on negative WOM intentions. 
Fig. 1 Study 1: conceptual model of the role of culture for the effects of price-related WOM and market mavenism on price perceptions

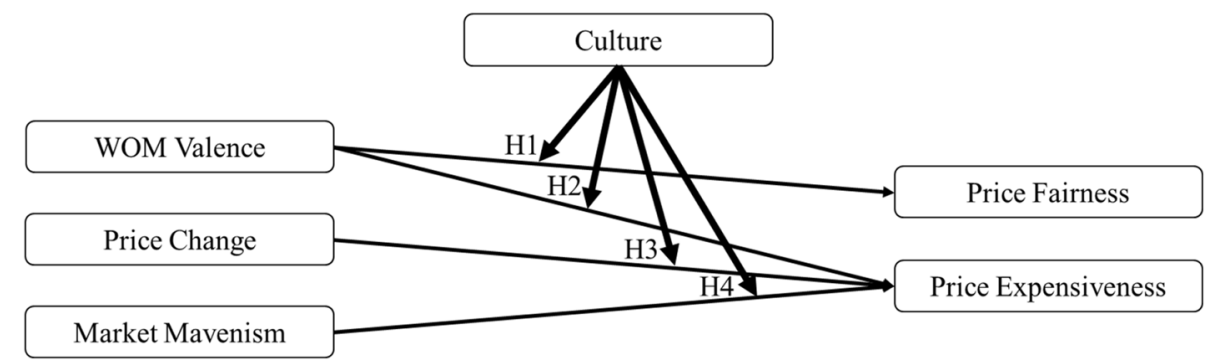

\section{Research design and findings}

\section{Study 1: cross-cultural effects of price-related WOM and market mavenism on price perceptions}

The first study was designed to compare the effects of pricerelated WOM on price perceptions in China and the United States. Specifically, the study focuses on a WOM receiver who is exposed to WOM from another individual in a faceto-face situation. The study measures the effects of culture on the relationship between WOM valence and price fairness and expensiveness perceptions as well as on the relationship between a recent price change communicated by WOM and perceived expensiveness. As market mavens are known to play an important role for WOM transmission and the presumption that their influence differs due to culture has been expressed, the present study extends this knowledge by evaluating their cross-cultural role in price expensiveness perceptions due to WOM and divides the sample into mavens and non-mavens (Goodey and East 2008; Slama et al. 2015; Stephen and Lehmann 2009) (Fig. 1).

\section{Method}

In four different scenarios, an online questionnaire put the participants in a realistic situation in which they had an urgent need for a new broadband internet connection and engaged in a conversation with another consumer in an offline setting after finding a product that met their expectations. In the four conditions, the participant's dialogue partner spoke either positively or negatively about the price and reported either a recent price increase or a recent price reduction. To ensure both a realistic situation and a perceptible manipulation, the price change was set at $20 \%$ in accordance with past studies (Gupta and Cooper 1992; Homburg et al. 2010; Marshall and Na 2000). Two pre-tests were performed prior to conducting the main study. The first pre-test sought to verify the manipulations of WOM valence and price change communicated by WOM within the scenarios. The sample $(n=190)$ consisted of doctoral and undergraduate students. The results confirmed that the scenarios differed significantly in WOM valence on a positive WOM scale $(\alpha=0.844$, Mpositive $=4.69$, Mnegative $=1.57$, $p<0.01)$ and a negative WOM scale $(\alpha=0.885$, Mpositive $=1.76$, Mnegative $=4.93, p<0.01)$ (Alexandrov et al. 2013). Additionally, $92.11 \%$ of the respondents were able to recall the price change correctly. The second pre-test was conducted among graduate and undergraduate students $(n=275)$ and sought to identify a suitable product for the experiment within the field of media product services. Compared to the other media services tested (cell phone contract and media streaming service), the broadband internet connection was perceived as the most expensive $(\alpha=0.911$, Minternet $=4.79$, Mcellphone $=4.14$, Mstreaming $=4.41$, $p<0.05$ ) (Yoo et al. 2000). The lowest WOM retransmission intention was found for the media streaming service while the cell phone contract and internet connection exhibited only a slight, insignificant difference (single-item, Minternet $=4.98$, Mcellphone $=5.17$, Mstreaming $=4.53, p<0.05$ ) (Baker et al. 2016). The author thus chose the product with the highest perceived expensiveness and a high WOM retransmission intention to ensure that the participants were able to empathize with the scenarios and perceive the object as relevant to the topic.

\section{Measures and sample}

The constructs were measured on reflective seven-point Likert-type multi-item scales ranging from "fully disagree" to "fully agree". The participants were divided into market mavens and non-market mavens by means of a median split (median $=5.5$ ). While the practice of using a median split has some disadvantages compared to continuous measures, it is the only way to guarantee consistency with the other factors and the cultural dimensions within this research. All items were modified to match the context of the study, and all reliability measurements exhibited satisfactory internal consistency: price expensiveness: $\alpha=0.861$ (Yoo et al. 2000), price fairness: $\alpha=0.937$ (Kwak et al. 2015), and market mavenism: $\alpha=0.928$ (Feick and Price 1987). The measurement model also fulfilled all of the remaining requirements.

The participants who obtained market mavenism scores exactly at the median point, sped through the questionnaire, failed to correctly solve an instructional manipulation check (IMC), or recalled the price change incorrectly were 
removed from the sample, resulting in a final total of 1006 observations that were considered in the analysis. The sample consists of respondents living in the United States and China and is representative of the two countries' populations concerning age and gender. All participants were recruited by a reputable external market-research company, which contributes to the independence of the results and improves the quality of the data due to active panel management. Each respondent was randomly assigned to one of the four conditions (negative valence and price reduction: 239; positive valence and price reduction: 253 ; negative valence and price increase: 258; positive valence and price increase: 256 ).

This study measured culture in accordance with the Values Survey Module (VSM) manual (Hofstede and Minkov 2013). Consequently, the cultural dimensions were calculated based on each country's mean scores rather than individual-level correlations. This approach meant that all respondents from each country were classified as either high or low on each of Hofstede's dimensions. The VSM was translated from English to Chinese by a native Chinese speaker from a translation agency with a focus on research translations. Afterwards, the translation was retranslated into English by two native speakers from China and additionally compared to the versions available from Hofstede (https:// geerthofstede.com). This study's VSM results confirmed the historical findings on all dimensions except for indulgence (https://geerthofstede.com). On this dimension, the present study found that China scored higher than the US (US: 60.34, China: 77.09). However, this study does not consider the indulgence dimension in the analyses. The results for all other dimensions matched Hofstede's findings, with the US scoring higher on individualism (US: 12.94, China: 5.82) and uncertainty avoidance (US: 4.95 , China: 0.00 , $\mathrm{C}($ ua $)=40.20$ ), and China scoring higher on power distance (US: 23.96, China: 24.89), masculinity (US: 0.00, China: $7.34, \mathrm{C}(\mathrm{mf})=0.28)$, and long-term orientation (US: 0.00 , China: 4.98, $\mathrm{C}(\mathrm{ls})=5.41)$. All dimensions were calculated using the index formulas and constants (C(ua), C(mf), C(ls)) listed in the VSM manual (Hofstede and Minkov 2013). As this study compares two cultures, the reliability of the VSM can be taken for granted at the country level (Hofstede and Minkov 2013). While all hypotheses are tested by strictly adhering to the instructions of the VSM, they are additionally examined on an individual level for each cultural dimension and each country separately. This procedure was recently presented by Roy et al. (2019) to examine whether cross-cultural effects persist within each country for the presented dimension.

\section{Manipulation checks}

Both manipulation checks (positive WOM scale $(\alpha=0.881$, Mpositive $=5.51$, SDpositive $=1.23$, Mnegative $=3.30$,
SDnegative $=1.81, \mathrm{p}<0.01)$ and negative $\mathrm{WOM}$ scale $(\alpha=0.905$, Mpositive $=2.77$, SDpositive $=1.61$, Mnegative $=5.12$, SDnegative $=1.73, \mathrm{p}<0.01)$ ) confirmed a significant difference between the scenarios with positively and negatively valanced WOM (Alexandrov et al. 2013). To ensure an effective manipulation of the price change communicated by WOM, only the respondents who were able to successfully recall the price change were taken into further consideration. Moreover, market mavenism was manipulated by employing the aforementioned median split while the difference between the two cultures was manipulated by taking into consideration only respondents from the corresponding country (US and China).

\section{Results}

Price expensiveness and price fairness exhibited a correlation of -0.452 , which was significant at the 0.01 level (2-tailed). Box's M had a value of 167.025 (F(45, $1,108,488)=3.664)$ and was significant at the conservative level of $p<0.001$. Pillai's trace was calculated instead of Wilk's lambda due to its robustness (Allen et al. 2008). Moreover, the equal sample sizes requirement was met, and a MANOVA could be performed.

The 2 (market mavenism: market maven versus nonmarket maven $) \times 2$ (WOM valence: positive versus negative) $\times 2$ (price change communicated by WOM: price reduction versus price increase) $\times 2$ (national culture: US versus China) MANOVA with the dependent variables perceived price expensiveness and price fairness revealed significant multivariate main effects for the postulated relationships: WOM valence (valence)*culture (Pillai's Trace $=0.014, \mathrm{~F}(2,989)=7.143, p=0.001$, partial $\eta^{2}=0.014$, obs. power $=0.932$, price change communicated by WOM (change)*culture (Pillai's Trace $=0.016$, $\mathrm{F}(2,989)=7.875, p<0.001$, partial $\eta^{2}=0.016$, obs. power $=0.953$ ) and market mavenism (maven)*culture (Pillai's Trace $=0.013, \mathrm{~F}(2,989)=6.462, p=0.002$, partial $\eta^{2}=0.013$, obs. power $=0.905$ ). Based on the significant results of the overall test, the postulated univariate effects were more closely examined. With respect to $\mathrm{H} 1$, a significant effect of valence* ${ }^{*}$ culture on price fairness was observable $\left(\mathrm{F}(1,990)=7.433, p=0.007\right.$, partial $\eta^{2}=0.007$, obs. power $=0.778$ ). A pairwise comparison indicated that the American respondents' price fairness perceptions shifted more strongly in response to negative pricerelated WOM compared to the Chinese respondents (US: Mpositive $=5.23$, SDpositive $=1.30$, Mnegative $=4.26$, SDnegative $=1.75, \mathrm{p}<0.001 ;$ China: Mpositive $=5.70$, SDpositive $=1.22$, Mnegative $=5.23$, SDnegative $=1.65$, $p<0.001)$. The two cultures also significantly differed in both price-related WOM valence manipulations (positive valence: $p<0.001$; negative valence: $p<0.001$ ). As the 
Americans scored higher on individualism and uncertainty avoidance, $\mathrm{H} 1$ was supported. Additionally, The Chinese respondents had higher price fairness perceptions in general. Their perceived price fairness in the negatively valanced price-related WOM scenario was equal to the American respondents' price fairness perceptions in the positively valanced price-related WOM scenario. Valence*culture also had a significant effect on perceived price expensiveness $(\mathrm{F}(1,990)=12.033, p=0.001$, partial $\eta^{2}=0.012$, obs. power $=0.934$ ). The Americans shifted their expensiveness perceptions more strongly in response to positively valanced price-related WOM compared to the Chinese respondents (US: Mpositive $=3.98$, SDpositive $=1.66$, Mnegative $=4.88$, SDnegative $=1.67$, $p<0.001$; China: Mpositive $=3.25$, SDpositive $=1.59$, Mnegative $=3.36$, SDnegative $=1.77, p=0.455$ ). There was also a significant difference between the US and China in both price-related WOM valence scenarios (positive valence: $p<0.001$; negative valence: $p<0.001$ ). Since the Americans were found to be more individualist and short-term oriented, H2 could be supported. The Chinese respondents perceived the product as less expensive in general and were not significantly influenced by the opinion of the WOM transmitter. With respect to $\mathrm{H} 3$, a significant effect of change*culture on perceived price expensiveness was found $(\mathrm{F}(1,990)=15.764, p<0.001$, partial $\eta^{2}=0.016$, obs. power $\left.=0.978\right)$. The positive effect of a price increase communicated by WOM on perceived expensiveness was smaller for the Chinese respondents compared to the US respondents (US: Mreduction $=3.78$, SDreduction $=1.76$, Mincrease $=5.07$, SDincrease $=1.42$, $\mathrm{p}<0.001$; China: Mreduction $=3.07$, SDreduction $=1.62$, Mincrease $=3.53$, SDincrease $=1.71, p=0.002$ ). The difference between the countries was significant in both the price reduction and the price increase scenarios (reduction: $p<0.001$; increase: $p<0.001)$. Given that Chinese culture scored higher on power distance and long-term orientation and lower on individualism and uncertainty avoidance, $\mathrm{H} 3$ could be supported.

As described above, all dimensions were also tested on an individual level within both countries separately to determine whether the postulated effects were sustained. For H1 and $\mathrm{H} 3$, no significant effects were verifiable for either the US or China. For H2, an effect of individualism (IDV) was visible within Chinese culture. Although the differences between individualist and collectivist consumers were not significant, the tendency supported the outcomes from the cross-cultural comparison: While positive valence lead to a lower perceived price expensiveness for the individualists, it lead to an even higher expensiveness perception for the collectivists (US: not significant; China: sig.: 0.059; positive valence: MhighIDV =3.17, SDhighIDV: 1.59 , MlowIDV $=3.46$, SDlowIDV: $1.57 ; \mathrm{p}=0.175$; negative valence:
MhighIDV $=3.42$, SDhighIDV: 1.74, MlowIDV $=3.21$, SDlowIDV: $1.86, p=0.404$ ).

Furthermore, the Chinese respondents perceived the product as less expensive in general. Maven*culture also had a significant effect on perceived price expensiveness $\left(\mathrm{F}(1,990)=12.885, p<0.001\right.$, partial $\eta^{2}=0.013$, obs. power $=0.948$ ). There was a stronger effect of market mavenism on perceived expensiveness among the Chinese respondents than among the US respondents (US: Mnonmaven $=4.45$, SDnon- maven $=1.71$, Mmaven $=4.40$, SDmaven $=1.75, p=0.766$; China: Mnon-maven $=2.95$, SDnonmaven $=1.63$, Mmaven $=3.57$, SDmaven $=1.67, p<0.001$ ). The difference between the cultures was significant for both the market mavens and the non-mavens (non-maven: $p<0.001$; maven: $p<0.001)$. Since the Chinese respondents scored higher on masculinity and power distance and lower on uncertainty avoidance, $\mathrm{H} 4$ could be supported. While the US respondents perceived the product to be more expensive in general, the difference between mavens and non-mavens was not significant. Nevertheless, the two groups differ in the opposite direction in tendency in the US compared to China. In China, the market mavens perceive the product to be more expensive than the non-mavens. Conversely, the American mavens perceive the product to be slightly less expensive compared to non-mavens.

Concerning individual-level analysis, there were visible effects for masculinity (MAS) in the US and China and for power distance (PDI) in China. While the impact of MAS was ambiguous (US: sig.: 0.092; non-maven: MhighMAS $=4.49$, SDhighMAS $=1.67$, MlowMAS $=4.36$, SDlowMAS $=1.81, p=0.524$; maven: MhighMAS $=4.29$, SDhighMAS $=1.72$, MlowMAS $=4.89$, SDlowMAS $=1.82$, $\mathrm{p}=0.057$; China: sig.: 0.131; non-maven: MhighMAS $=3.04$, SDhighMAS $=1.60$, MlowMAS $=2.78$, SDlowMAS $=1.69, p=0.277$; maven: MhighMAS $=3.55$, SDhighMAS $=1.66$, MlowMAS $=3.66$, SDlowMAS $=1.71$, $p=0.626$ ), PDI showed a tendency substantiating the crosscultural outcomes (US: not significant; China: sig.: 0.094; non-maven: MhighPDI $=2.86$, SDhighPDI $=1.67$, Mlow$\mathrm{PDI}=3.13$, SDlowPDI $=1.56, p=0.236$; maven: Mhigh$\mathrm{PDI}=3.69$, SDhighPDI $=1.81$, MlowPDI $=3.43$, SDlow$\mathrm{PDI}=1.49, p=0.179$ ).

\section{Discussion}

All postulated effects with respect to price fairness and expensiveness perceptions could be supported in a crosscultural context, and some persisted even in an individuallevel analysis. Negatively valanced price-related WOM had a negative effect on price fairness perceptions, and individualism and uncertainty avoidance further strengthened this effect. As these traits are high among individuals living in the US, the effect is especially strong in this culture. Chinese 
Fig. 2 Study 2: conceptual model of the role of culture in the effects of price-related WOM and WOM diffusion

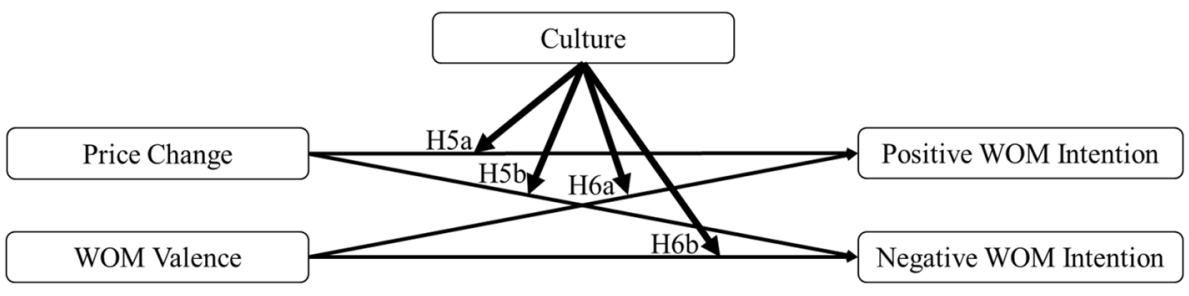

consumers perceived higher price fairness in general compared to Americans. Positively valanced price-related WOM led to lower perceived expensiveness compared to negatively valanced price-related WOM, and this effect was especially strong for the highly individualistic and short-term-oriented US culture. The Chinese residents' expensiveness perceptions are not substantially influenced by the opinion of a price-related WOM transmitter. The Chinese and American consumers also reacted differently to learning about a price change in a WOM conversation. The Chinese respondents exhibited smaller changes in expensiveness perceptions in response to a price increase compared to individuals from the US. Consequently, price increases spread by WOM seem to have a weaker effect in power distant, long-term oriented and collectivist cultures with low uncertainty avoidance. Moreover, a stronger effect of market mavenism on perceived expensiveness was found in China. Although there was no significant effect in the US, the tendency was opposite to that of China, where the mavens perceive higher expensiveness. Across all manipulations, the Chinese consumers generally perceived the product to be less expensive than those living in the US. Ultimately, all comparisons between the two cultures revealed significant differences. This outcome suggests an overall presence of distinct price perceptions resulting from price-related WOM and market mavenism between the US and Chinese cultures.

\section{Study 2: cross-cultural comparison of price-related WOM diffusion}

Study 2 aimed to shed light on differences in price-related WOM dissemination intentions between the Chinese and US cultures. For this purpose, the impact of culture on the effects of WOM valence and a price change communicated by WOM on subsequent positive and negative WOM intentions was measured to determine which nation offers greater opportunities for price-related WOM diffusion. (Fig. 2).

Method and Sample. To obtain comparable outcomes, WOM valence and the price change communicated by WOM were manipulated in the same way as in Study 1. Culture was manipulated by surveying respondents from China and the US and adhering to the VSM manual (Hofstede and Minkov 2013). Both countries' samples were representative of their populations with respect to age and gender. The data was collected following the same procedure as in Study 1. A total of 1054 respondents were included in the analyses after excluding the respondents who failed to pass the IMC, sped through the process, or recalled the price change incorrectly (negative valence and price reduction: 255 ; positive valence and price reduction: 261 ; negative valence and price increase: 274; positive valence and price increase: 264 ).

\section{Measures}

Positive WOM intention and negative WOM intention were measured with reflective multi-item seven-point Likert-type scales ( $1=$ "fully disagree" and $7=$ "fully agree"). Both scales exhibited satisfactory internal consistency: positive WOM intention yielded $\alpha=0.923$ (Price and Arnould 1999), and negative WOM intention showed $\alpha=0.930$ (Ashley and Noble 2014).

With respect to the VSM, all dimensions were again in accordance with Hofstede's historical findings except for indulgence, with China scoring higher on power distance (US: 23.55, China: 24.39), masculinity (US: 0.00, China: 7.87, $\mathrm{C}(\mathrm{mf})=0.88)$, long-term orientation (US: 0.00, China: 4.15, C(ls) =4.83) and indulgence (US: 59.99, China: 77.27) and the US scoring higher on individualism (US: 12.57, China: 6.40) and uncertainty avoidance (US: 5.24, China: 0.00, C(ua) $=40.29)($ https://geerthofstede.com). However, as in Study 1, the indulgence dimension was not included in the analysis. Furthermore, individual-level analysis was performed for each relevant dimension and in each culture separately to check whether the cross-cultural effects were sustained.

\section{Manipulation checks}

Following the same procedure as in Study 1, the successful manipulation of the price change communicated by WOM was ensured by including only those respondents in the analyses who were able to recall the price change correctly. The manipulation checks for WOM valence showed outcomes comparable to Study 1, indicating significant differences between groups on both the positive and negative WOM scales (positive WOM scale $(\alpha=0.880$, Mpositive $=5.52$, SDpositive $=1.22$, Mnegative $=3.29$, SDnegative $=1.80$, $p<0.01)$ and negative WOM scale $(\alpha=0.907$, Mpositive $=2.75$, SDpositive $=1.60$, Mnegative $=5.16$, SDnegative $=1.71, p<0.01)$ ). 


\section{Results}

Due to low correlations among the two dependent variables, two separate ANOVAs were performed. Both ANOVAs were calculated in a 2 (change: reduction versus increase) $\times 2$ (valence: positive versus negative) $\times 2$ (culture: US versus China) design. The first ANOVA with positive WOM intention as the dependent variable showed significant effects of change* culture $(\mathrm{F}(1,1046)=6.168, p=0.013$, partial $\eta^{2}=0.006$, obs. power $\left.=0.699\right)$ and valence* ${ }^{*}$ culture $\left(\mathrm{F}(1,1046)=4.365, p=0.037\right.$, partial $\eta^{2}=0.004$, obs. power $=0.551)$. A price reduction generally led to a higher positive WOM intention than a price increase (Mreduction $=5.15$, SDreduction $=1.50$, Mincrease $=4.61$, SDincrease $=1.73, \mathrm{p}<0.001$ ), and American culture strengthened the negative effect of a price increase communicated among consumers on subsequent positive WOM intention (US: Mreduction $=4.94$, SDreduction $=1.58$, Mincrease $=4.14$, SDincrease $=1.84, p<0.001$; China: Mreduction $=5.38$, SDreduction $=1.37$, Mincrease $=5.05$, SDincrease $=1.51$, $p=0.010$ ). The difference between the two countries was significant in both the price reduction and the price increase scenarios (reduction: $p=0.001$; increase: $p<0.001$ ). As US culture scored high on individualism and low on power distance and masculinity; thus, H5a was supported. Individuallevel analysis could not detect any significant effects for the relevant dimensions and within any culture.

As expected, positively valanced price-related WOM generally led to higher positive WOM intentions compared to negatively valenced WOM (Mpositive $=5.45$, SDpositive =1.28, Mnegative =4.31, SDnegative $=1.77$, $\mathrm{p}<0.001)$. American culture strengthened this effect (US: Mpositive $=5.21$, SDpositive $=1.46$, Mnegative $=3.88$, SDnegative $=1.78, p<0.001$; China: Mpositive $=5.67$, SDpositive $=1.04$, Mnegative $=4.74$, SDnegative $=1.64$, $p<0.001$ ), and the comparison between the two nations was significant (positive: $p<0.001$; negative: $p<0.001$ ). Since the US scored higher on individualism compared to China, H6a was supported. However, this finding could not be replicated within countries on an individual level. Furthermore, the Chinese respondents had generally higher positive WOM intention in every scenario.

The second ANOVA analyzed the effects on negative WOM intention. With respect to Hypotheses $\mathrm{H} 5 \mathrm{~b}$ and $\mathrm{H} 6 \mathrm{~b}$, significant effects of change*culture $(F(1,1046)=6.351$, $p=0.012$, partial $\eta^{2}=0.006$, obs. power $\left.=0.712\right)$ and valence*culture $(\mathrm{F}(1,1046)=2.891, p=0.089$, partial $\eta^{2}=0.003$, obs. power $=0.397$ ) were found. As expected, a price increase communicated by WOM led to higher negative WOM intention compared to a price reduction (Mreduction $=3.44$, SDreduction $=1.76$, Mincrease $=4.05$, SDincrease $=1.79, \mathrm{p}<0.001)$. American culture further strengthened this effect (US: Mreduction=3.05,
SDreduction $=1.72$, Mincrease $=3.91$, SDincrease $=1.85$, $p<0.001$; China: Mreduction $=3.85$, SDreduction $=1.70$, Mincrease $=4.18$, SDincrease $=1.73, p=0.024)$. The difference between the two countries was significant for the price reduction and the price increase scenario (reduction: $p<0.001$; increase: $p=0.082$ ). As the US culture scores higher on individualism, low power distance and femininity, H5b was supported. On an individual level, an effect of IDV was visible only in China. Surprisingly, IDV had an opposite influence within this culture (US: not significant; China: sig.: 0.041; price reduction: MhighIDV $=3.86$, SDhigh$\mathrm{IDV}=1.69$, MlowIDV = 3.81, SDlowIDV = 1.74, $\mathrm{p}=0.838$; price increase: MhighIDV $=3.95$, SDhighIDV $=1.74$, MlowIDV $=4.69$, SDlowIDV $=1.59, p=0.001)$.

Negatively valanced price-related WOM generally led to higher negative WOM intentions (Mpositive $=3.22$, SDpositive $=1.74$, Mnegative $=4.28$, SDnegative $=1.70$, $p<0.001)$. This effect was stronger in Chinese culture (US: Mpositive =3.03, SDpositive =1.77, Mnegative =3.93, SDnegative $=1.79, p<0.001 ;$ China: Mpositive $=3.41$, SDpositive $=1.69$, Mnegative $=4.63$, SDnegative $=1.53$, $p<0.001)$, and the difference in the US was significant (positive: $p=0.011$; negative: $p<0.001$ ). Because China is a more collectivist nation than the US, this finding supports H6b. Moreover, just as the Chinese respondents exhibited generally higher positive WOM intentions, they also exhibited higher negative WOM intentions. Furthermore, this effect could also be replicated on an individual level within the US (US: sig.: 0.065; positive valence: MhighIDV =3.12, SDhighIDV $=1.78$, MlowIDV $=2.71$, SDlowIDV $=1.69$, $p=0.126$; negative valence: MhighIDV $=3.84$, SDhigh$\mathrm{IDV}=1.83$, MlowIDV $=4.22, \mathrm{SDlowIDV}=1.65, p=0.158$; China: not significant).

\section{Discussion}

Study 2, which was also based on Hofstede's national culture dimensions, indicated that Chinese culture is associated with a higher baseline positive and negative WOM intention after being exposed to WOM about prices. Conversely, the inhabitants of the US, a nation with individualist, low power distant and feminine traits, react more strongly to price changes communicated within a consumer discussion in terms of subsequent positive and negative WOM intentions. The findings with respect to the opinion of the pricerelated WOM transmitter are ambivalent. While a major difference in the effects of positively and negatively valanced price-related WOM on subsequent positive WOM intentions was found in the individualist US culture, the difference in effects on negative WOM intentions was stronger in the collectivist Chinese culture, which could also be replicated on an individual level within the US. 


\section{General discussion}

Since past research has assumed that culture plays an important role for WOM activities but has neglected to clarify cross-cultural differences in WOM behavior and price perceptions, the current study aimed to analyze cross-cultural differences in price-related WOM behavior (Abratt et al. 1995; Christiansen and Tax 2000; Christiansen and Tsiourtis 1998; Lalwani and Forcum 2016). To reach this goal, Study 1 shed light on shifts in consumer price perceptions due to WOM in the Chinese and US cultures while Study 2 examined WOM intentions following exposure to price-related WOM to better understand WOM diffusion. Hofstede's (1980) national culture dimensions were used to model the two nations' underlying cultural traits and to postulate the corresponding hypotheses.

Study 1 found that Chinese individuals have higher price fairness perceptions and lower price expensiveness perceptions than Americans. Therefore, it seems that the Chinese are generally less sensitive in their price-related judgments. Moreover, Americans' price fairness judgments were found to shift more strongly in response to negatively valanced price-related WOM compared to their Chinese counterparts. Drawing upon Hofstede's cultural dimensions, it can be assumed that American consumers' high levels of individualism and uncertainty avoidance lead to this sensitivity to price-related WOM valence.

A similar effect was visible in the cross-cultural analysis of price expensiveness perceptions. Americans' expensiveness perceptions showed greater shifts in response to positively valanced price-related WOM compared to those of Chinese residents, whose expensiveness judgments were only marginally influenced by the opinion of the WOM transmitter. In addition to individualism, the short-term orientation of consumers in the US seems have driven this effect. These findings are highly relevant for both researchers and practitioners as they illustrate the two cultures' very different reactions to the opinion of a WOM transmitter. While it is easy to convince consumers from individualist nations such as the US by sharing an opinion about a price, consumers from collectivist cultures such as China view product prices as fairer and less expensive but are not easily influenced by other individuals.

Furthermore, Chinese consumers' expensiveness perceptions are less influenced by learning about a price change in a conversation compared to individuals from the US who react more strongly to a price increase. It can be assumed that the cultural traits of high power distance, long-term orientation, collectivism and uncertainty avoidance prevent a price increase or reduction communicated via WOM from having a strong effect on Chinese consumers' expensiveness perceptions. Therefore, these price management tools are less effective in nations such as China compared to the US.

The present study confirms the important role of market mavenism for understanding consumer behavior. It could be shown that market mavens in China perceived the product as more expensive than the non-mavens did. Meanwhile, in the US, the effect was not strong but nonetheless pointed in a different direction, with the mavens perceiving the product as slightly less expensive than the non-mavens. It seems that masculinity and power distance strengthen the effect of market mavenism on price expensiveness perceptions whereas uncertainty avoidance weakens it. These mechanisms could lead to effects of mavenism in opposite directions in each culture. This finding emphasizes the opposing roles of market mavens in different cultures and highlights that companies should include consumers with a broad knowledge of markets in their pricing strategies.

While Study 1 shed light on the vast cross-cultural differences in price perceptions resulting from WOM, Study 2 found that the mechanisms of price-related WOM diffusion are also very distinct in the two cultures. The Chinese consumers exhibited generally higher baseline positive and negative WOM intentions after being exposed to pricerelated WOM. Therefore, it seems that Chinese residents have higher intentions to discuss price information obtained from consumer conversations than Americans. Conversely, learning about a price increase or reduction via a consumer conversation had a strong effect on Americans' subsequent positive and negative WOM intentions compared to those of Chinese consumers. It is assumed that the Americans' individualist, low power distant and feminine traits are responsible for this behavior. Price changes can easily lead to self-reinforcing mechanisms in both cultures as part of WOM diffusion. However, the risks and opportunities are lower in cultures such as China where residents spread a high amount of WOM about prices but do not react as sensitively as Americans to price changes in terms of the negativity and positivity of their subsequent WOM intentions. The study also examined the WOM transmitter's positive versus negative opinions about the price and found ambivalent outcomes for the two nations. On one hand, the individualist US consumers showed a large difference between positive and negative price-related WOM concerning their subsequent positive WOM intentions. On the other hand, the collectivist Chinese showed a greater difference between positively and negatively valanced WOM when forming their subsequent negative WOM intentions. This finding highlights a risk of price-related WOM in Chinese culture. Not only do collectivists have higher WOM intention, but a WOM transmitter's negative opinion of the product's price leads to a strong intention to further spread that negative opinion via WOM. Although Americans react more strongly to the valence of a WOM transmitter concerning their positive 
WOM intentions, the higher baseline WOM intention in Chinese culture still leads to higher positive WOM intentions in all cases. Thus, price-related WOM diffusion is a fasterpaced process in China even though Americans are more easily influenced in certain situations.

While some outcomes from the cross-cultural comparison could be replicated on an individual level within each culture for the relevant dimensions, many effects were not visible in such a setting. This finding implies strong differences among cultures that are not verifiable within a nation when considering cultural dimensions.

\section{Theoretical contributions}

As the present study revolved around Hofstede's national culture dimensions, it contributes to the understanding and applicability of this theoretical framework and shows that Hofstede's concept is applicable to the topic of pricerelated WOM. It demonstrates that Hofstede's national culture dimensions are well-suited for distinguishing between the Chinese and US cultures to understand differences in price perceptions and WOM transmission intentions following exposure to price-related WOM. To further clarify the role of each dimension, the study also incorporated individual-level analyses within each society. In this context, some cross-cultural differences could not be broken down to individual differences within a country. This finding confirms the approach that national culture is strictly separated from individual personality types and underscores Hofstede's understanding that cultural dimensions cannot necessarily be employed for individual-level analysis (Hofstede and Minkov 2013). Hofstede's historical findings as well as most subsequent studies for American and Chinese culture are confirmed, except for the indulgence dimension, which was surprisingly higher for Chinese consumers (https://geert hofstede.com).

Apart from Hofstede's national culture dimensions, several further theories were used to postulate direct effects before considering the impact of national culture. The study showed that the dual entitlement principle and the P-O-X model are well-suited for understanding the effect of the valance of a WOM transmitter's opinion on the recipient's subsequent price fairness and expensiveness perceptions. As past studies have described the role of the dual entitlement principle to explain price fairness perceptions, the current study was able to confirm its exploratory power to be applicated to price-WOM leading to adapted fairness perceptions (Campbell, 1999; Homburg et al., 2005). Furthermore, this study was able to show that consumers' desired balance in a triadic relationship, which is elaborated upon by the P-O-X model, has an influence on their expensiveness perceptions (Heider, 1946; Hummon \& Doreian, 2003).
While individuals had different patterns in behavior in both cultures, they always intended to resolve potential cognitive dissonance by adapting their expensiveness perception towards the WOM transmitter. Prospect theory was successfully used to show that a price change can have an impact on subsequent WOM intentions. While past research has evaluated this mechanism for actual visible price changes, the current study confirmed its applicability for price changes being communicated only in a consumer discussion (Marshall and $\mathrm{Na} 2000$ ).

Moreover, the results of this study emphasize the unique role of market mavenism in different cultures. While the Chinese market mavens generally perceived the product to be more expensive than the non-mavens following exposure to price-related WOM, the difference between mavens and non-mavens was only marginal in the US and in the reverse direction. This finding suggests that market mavenism can play completely different roles in the context of price-related WOM and price perceptions in different cultures. As expensiveness perceptions have been found to influence consumers' purchase intentions, it is questionable whether market mavens are conducive for product diffusion cycles in China (Huettl and Gierl 2012). More research on the role of market mavenism across cultures is highly recommended.

\section{Managerial implications}

As this research is the first to address price-related WOM from a cross-cultural perspective, it contributes not only to theory, but it also offers valuable insights to practitioners. One of the main findings concerns Chinese consumers' higher price-related positive and negative baseline WOM intentions following exposure to price-related WOM compared to Americans. Consequently, managers can more easily spread price information via WOM in countries with cultural traits such as those of China. These types of potentially self-reinforcing cycles are not as easy to initiate in cultures such as the US. However, this fast-moving process presents not only opportunities but also risks as this study found both high positive and high negative WOM intentions upon the reception of price-related WOM in Chinese culture. Hence, when attempting to initiate price-related WOM in such cultures, it is important to consider the influential role of ingroups. Past research has illustrated that collectivist Chinese individuals react more sensibly to price comparisons within their in-group (e.g., friends) compared to out-groups (e.g., strangers) (Bolton et al. 2010). Against this background, the present study's findings should encourage practitioners to initiate price-related WOM across different in-groups to maximize diffusion.

The present study found that price changes communicated via WOM have a stronger effect on price expensiveness 
perceptions as well as positive and negative WOM intentions in the US compared to China. This finding is in line with past findings that higher price changes are necessary in Asia compared to the US for consumers to recognize them (Marshall and $\mathrm{Na} 2000$ ). Therefore, pricing managers must consider the higher sensitivity to price changes in individualist Western cultures compared to collectivist Asian cultures, even when such price changes are only experienced as a WOM message. Consequently, smaller price changes will be necessary in the US than in China to reach the same outcomes in terms of price perceptions and WOM dissemination. However, this study also showed that Chinese individuals have higher baseline positive and negative WOM intentions as well as lower expensiveness perceptions.

Another finding of great relevance for practitioners is the ambivalent role of market mavens across cultures. Whereas the Chinese market mavens generally perceived the product as more expensive compared to the non-mavens, there was only a slight difference between the mavens and the nonmavens in the US, but in the opposite direction. As mavens have a high tendency to transmit messages and share their broad knowledge, they can pose a threat with respect to price-related WOM in masculine and power distant cultures (Goodey and East 2008; Kaplan and Haenlein 2011). They could spread their perception of the product as highly expensive to other consumers and negatively influence them. The current study does not find evidence of such a risk among American mavens. Instead, they could function as advocates of products' affordability. Moreover, the research by Goodey and East (2008) indicates that it is crucial to target male and female market mavens differently. While male mavens are sensitive to social status and prestige, their female counterparts prioritize reassurance, potentially by focusing on environmental or social support (Goodey and East 2008).

\section{Limitations and directions for future research}

This article employed the Values Survey Module to compare two national samples (the US and China) and to categorize their underlying cultural traits. However, it should be noted that this research is based on online surveys while the Values Survey Module was designed as a paper-and-pencil questionnaire. Moreover, some of the cultural values in this study differed only slightly across the two countries. Nevertheless, the author followed recommendations to examine countrylevel correlations rather than individual-level correlations as the goal was to explore cross-cultural differences. While these outcomes were used to test the study's hypotheses, additionally testing was conducted to determine whether the effects were sustained in an individual-level analysis within each country separately. Some effects could be replicated within each nation. However, a large share of postulations was not verifiable on an individual level. While this finding substantiates Hofstede's criticism about using the VSM for individual-level analysis, it also raises questions about the role of the dimensions or potential other drivers of cross-cultural differences in price-related WOM (Hofstede and Minkov 2013). Further research on this issue is highly encouraged.

The study also followed recommended index calculation formulas and considered mean scores (Hofstede and Minkov 2013). This approach meant that power distance and longterm orientation differed by less than five units across the two nations in both studies while the same was true of uncertainty avoidance in Study 1. As the reliability of the VSM can be taken for granted at the country level and the differences between the scores were not found to be significant, future research should involve countries that differ more strongly on these dimensions (Hofstede and Minkov 2013).

Moreover, while this research has highlighted the ambivalent role of market mavenism across cultures and established manifold avenues for future research on this topic, it must be mentioned that the median score of 5.5 for market mavenism was very high. Future studies with samples scoring lower on market mavenism might gain different insights. Furthermore, future research may wish to also examine social ties as in-groups play an important role in Chinese culture and may also do so in the context of price-related WOM (Bolton et al. 2010). Nevertheless, while leaving these opportunities for future research, the present study has obtained highly relevant insights that can aid both marketing scholars and practitioners in understanding the powerful process of pricerelated WOM from a cross-cultural perspective.

Supplementary Information The online version contains supplementary material available at https://doi.org/10.1057/s41272-021-00337-8.

Funding Open Access funding enabled and organized by Projekt DEAL.

Open Access This article is licensed under a Creative Commons Attribution 4.0 International License, which permits use, sharing, adaptation, distribution and reproduction in any medium or format, as long as you give appropriate credit to the original author(s) and the source, provide a link to the Creative Commons licence, and indicate if changes were made. The images or other third party material in this article are included in the article's Creative Commons licence, unless indicated otherwise in a credit line to the material. If material is not included in the article's Creative Commons licence and your intended use is not permitted by statutory regulation or exceeds the permitted use, you will need to obtain permission directly from the copyright holder. To view a copy of this licence, visit http://creativecommons.org/licenses/by/4.0/. 


\section{References}

Abratt, R., D. Nel, and C. Nezer. 1995. Role of the market maven in retailing: A general marketplace influencer. Journal of Business and Psychology 10 (1): 31-55.

Ahluwalia, R. 2002. How prevalent is the negativity effect in consumer environments? Journal of Consumer Research 29 (2): 270-279.

Alexandrov, A., B. Lilly, and E. Babakus. 2013. The effects of socialand self-motives on the intentions to share positive and negative word of mouth. Journal of the Academy of Marketing Science 41 (5): 531-546.

Allen, M., S. Titsworth, and S.K. Hunt. 2008. Quantitative research in communication. Thousand Oaks, CA: Sage.

Allsopp, D.T., B.R. Bassett, and J.A. Hoskins. 2007. Word-of-mouth research: Principles and applications. Journal of Advertising Research 47 (4): 398-411.

Anderson, E.W. 1998. Customer satisfaction and word-of-mouth. Journal of Service Research 1 (1): 5-17.

Ashley, C., and S.M. Noble. 2014. It's closing time: Territorial behaviors from customers in response to front line employees. Journal of Retailing 90 (1): 74-92.

Bagwell, K., and M.H. Riordan. 1991. High and declining prices signal product quality. The American Economic Review 81 (1): 224-239.

Baker, A.M., N. Donthu, and V. Kumar. 2016. Investigating how word-of-mouth conversations about brands influence purchase and retransmission intentions. Journal of Marketing Research 53 (2): 225-239.

Bansal, H.S., and P.A. Voyer. 2000. Word-of-mouth processes within a services purchase decision context. Journal of Service Research 3 (2): 166-177.

Bolton, L.E., H.T. Keh, and J.W. Alba. 2010. How do price fairness perceptions differ across culture? Journal of Marketing Research 47 (3): 564-576.

Bone, P.F. 1995. Word of mouth effects on short-term and longterm product judgments. Journal of Business Research 32 (3): 213-223.

Breazeale, M. 2009. Word of mouse. International Journal of Market Research 51 (3): 297-318.

Bristor, J.M. 1990. Enhanced explanations of word of mouth communications: The power of relationships. Research in Consumer Behavior 4: 51-83.

Brown, J.J., and P.H. Reingen. 1987. Social ties and word-of-mouth referral behavior. Journal of Consumer Research 14 (3): 350-362.

Budde-Sung, A. 2013. The invisible meets the intangible: Culture's impact on intellectual property protection. Journal of Business Ethics 117 (2): 345-359.

Bughin, J., J. Doogan, and O.J. Vetvik. 2010. A new way to measure word-of-mouth marketing. McKinsey Quarterly 2: 113-116.

Campbell, M.C. 1999. Perceptions of price unfairness: Antecedents and consequences. Journal of Marketing Research 36 (2): 187-199.

Campbell, M.C. 2007. 'Says Who?!' How the source of price information and affect influence perceived price (un)fairness. Journal of Marketing Research 44 (2): 261-271.

Chevalier, J.A., and D. Mayzlin. 2006. The effect of word of mouth on sales. Journal of Marketing Research 43 (3): 345-354.

Christiansen, T., and S.S. Tax. 2000. Measuring word of mouth: The questions of who and when? Journal of Marketing Communications 6 (3): 185-199.

Christiansen, T. and P. Tsiourtis. 1998. Market mavens in Cyprus: A reality or just mavens in their own minds? In American Marketing Association (AMA) Conference Proceedings (Vol. 9, p. 288). American Marketing Association.
Christie, P.M.J., I.W.G. Kwon, P.A. Stoeberl, and R. Baumhart. 2003. A cross-cultural comparison of ethical attitudes of business managers: India Korea and the United States. Journal of Business Ethics 46 (3): 263-287.

Du, R.Y., and W.A. Kamakura. 2008. Where did all that money go? Understanding how consumers allocate their consumption budget. Journal of Marketing 72 (6): 109-131.

Dwyer, S., H. Mesak, and M. Hsu. 2005. An exploratory examination of the influence of national culture on cross-national product diffusion. Journal of International Marketing 13 (2): 1-27.

Engel, J.F., R.D. Blackwell, and R.J. Kegerreis. 1969. How information is used to adopt an innovation. Journal of Advertising Research 9 (4): 3-8.

Feick, L.F., and L.L. Price. 1987. The market maven: A diffuser of marketplace information. Journal of Marketing 51 (1): 83-97.

Feldman, J.M., and J.G. Lynch. 1988. Self-generated validity and other effects of measurement on belief, attitude, intention, and behavior. Journal of Applied Psychology 73 (3): 421-435.

Fornerino, M. 2003. Internet adoption in France. The Service Industries Journal 23 (1): 119-135.

Frank, B., T. Enkawa, and S.J. Schvaneveldt. 2014. How do the success factors driving repurchase intent differ between male and female customers? Journal of the Academy of Marketing Science 42 (2): 171-185.

Frank, B., T. Enkawa, and S.J. Schvaneveldt. 2015. The role of individualism vs. collectivism in the formation of repurchase intent: A cross-industry comparison of the effects of cultural and personal values. Journal of Economic Psychology 51: 261-278.

Godes, D., and D. Mayzlin. 2004. Using online conversations to study word-of-mouth communication. Marketing Science 23 (4): $545-560$.

Goldsmith, R.E., and D. Horowitz. 2006. Measuring motivations for online opinion seeking. Journal of Interactive Advertising 6 (2): $1-16$.

Goldenberg, J., B. Libai, and E. Muller. 2001. Talk of the network: A complex systems look at the underlying process of word-ofmouth. Marketing Letters 12 (3): 211-223.

Goles, T., V.R. Srinivasan, S. Lee, and J. Warren. 2009. Trust violation in electronic commerce: Customer concerns and reactions. Journal of Computer Information Systems 49 (4): 1-9.

Goodey, C., and R. East. 2008. Testing the market maven concept. Journal of Marketing Management 24 (3-4): 265-282.

Guadalupi, C. 2018. Learning quality through prices and word-ofmouth communication. Journal of Economics \& Management Strategy 27 (1): 53-70.

Gupta, S., and L.G. Cooper. 1992. The discounting of discounts and promotion thresholds. Journal of Consumer Research 19 (3): 401-411.

Haws, K.L., and W.O. Bearden. 2006. Dynamic pricing and consumer fairness perceptions. Journal of Consumer Research 33 (3): 304-311.

Heider, F. 1946. Attitudes and cognitive organization. Journal of Psychology 21 (1): 107-112.

Heine, S.J., D.R. Lehman, H.R. Markus, and S. Kitayama. 1999. Is there a universal need for positive self-regard? Psychological Review 106 (4): 766-794.

Hennig-Thurau, T., and G. Walsh. 2004. Electronic word-of-mouth: Motives for and consequences of reading consumer articulations on the internet. International Journal of Electronic Commerce 8 (2): 51-74.

Herr, P.M., F.R. Kardes, and J. Kim. 1991. Effects of word-of-mouth and product-attribute information on persuasion: An accessibility-diagnosticity perspective. Journal of Consumer Research 17 (4): 454-462. 
Hervas-Drane, A. 2015. Recommended for you: The effect of word of mouth on sales concentration. International Journal of Research in Marketing 32 (2): 207-218.

Hirschman, E.C. 1980. Innovativeness, novelty seeking, and consumer creativity. Journal of Consumer Research 7 (3): 283-295.

Ho, D.Y. 1976. On the concept of face. American Journal of Sociology 81 (4): 867-884.

Hofstede, G. 1980. Culture's consequences: International differences in work-related values. Beverly Hills, CA: Sage.

Hofstede, G. 1983. The cultural relativity of organizational practices and theories. Journal of International Business Studies 14 (2): $75-89$.

Hofstede, G. 2001. Culture's consequences: Comparing values, behaviors, institutions and organizations across nations, $2 \mathrm{nd}$ ed. Thousand Oaks, CA: Sage.

Hofstede, G. and. M. Minkov. 2013. Values survey module 2013 manual.

Homburg, C., W.D. Hoyer, and N. Koschate. 2005. Customers' reactions to price increases: Do customer satisfaction and perceived motive fairness matter? Journal of the Academy of Marketing Science 33 (1): 36-49.

Homburg, C., N. Koschate, and D. Totzek. 2010. How price increases affect future purchases: The role of mental budgeting, income, and framing. Psychology \& Marketing 27 (1): 36-53.

Hood, J.N., and J.M. Logsdon. 2002. Business ethics in the NAFTA countries: A cross-cultural comparison. Journal of Business Research 55 (11): 883-890.

Huettl, V., and H. Gierl. 2012. Visual art in advertising: The effects of utilitarian vs. hedonic product positioning and price information. Marketing Letters 23 (3): 893-904.

Hummon, N.P., and P. Doreian. 2003. Some dynamics of social balance processes. Bringing Heider back into balance theory. Social Networks 25 (1): 17-49.

Kahneman, D., and A. Tversky. 1979. Prospect theory: An analysis of decision under risk. Econometrica 47 (2): 263-291.

Kaplan, A.M., and M. Haenlein. 2011. Two hearts in three-quarter time: How to waltz the social media/viral marketing dance. Business Horizons 54 (3): 253-263.

Katz, E., and P.F. Lazarsfeld. 1955. Personal influence. Glencoe, IL: Free Press.

Kozinets, R.V., K. de Valck, A.C. Wojnicki, and S.J.S. Wilner. 2010. Networked narratives: Understanding word-of-mouth marketing in online communities. Journal of Marketing 74 (2): 71-89.

Kwak, H., M. Puzakova, and J.F. Rocereto. 2015. Better not smile at the price: The differential role of brand anthropomorphization on perceived price fairness. Journal of Marketing 79 (4): $56-76$.

Lalwani, A.K., and L. Forcum. 2016. Does a dollar get you a dollar's worth of merchandise? The impact of power distance belief on price-quality judgments. Journal of Consumer Research 43 (2): $317-333$.

Lee, J.A. 2000. Adapting Triandis's model of subjective culture and social behavior relations to consumer behavior. Journal of Consumer Psychology 9 (2): 117-126.

Lexis, K., A. Huetten, and F. Siems. 2013. Antecedents and target groups of word-of-mouth communication of prices: Theory and new empirical results. Journal of International Business and Economics 13 (3): 77-86.

Liu, Y. 2006. Word of mouth for movies: Its dynamics and impact on box office revenue. Journal of Marketing 70 (3): 74-89.

Lund, D.J., L.K. Scheer, and I.V. Kozlenkova. 2013. Culture's impact on the importance of fairness in interorganizational relationships. Journal of International Marketing 21 (4): 21-43.

Lynch, J.G., Jr. 2006. Accessibility-diagnosticity and the multiple pathway anchoring and adjustment model. Journal of Consumer Research 33 (1): 25-27.
Lynch, J.G., Jr., H. Marmorstein, and M.F. Weigold. 1988. Choices from sets including remembered brands: Use of recalled attributes and prior overall evaluations. Journal of Consumer Research 15 (2): 169-184.

Markus, H.R., and S. Kitayama. 1991. Culture and the self: Implications for cognition, emotion, and motivation. Psychological Review 98 (2): 224-253.

Marshall, R., and W. Na. 2000. How much is enough? A preliminary empirical study of the price tolerance zone in Singapore. Advances in Consumer Research 27: 30-33.

Maxwell, S. 1999. Biased attributions of a price increase: Effects of culture and gender. Journal of Consumer Marketing 16 (1): 9-23.

Milgrom, P., and J. Roberts. 1986. Price and advertising signals of product quality. Journal of Political Economy 94 (4): 796-821.

Moon, Y.S., and G.R. Franke. 2000. Cultural influences on agency practitioners' ethical perceptions: A comparison of Korea and the US. Journal of Advertising 29 (1): 51-65.

Murray, K.B. 1991. A test of services marketing theory: Consumer information acquisition activities. Journal of Marketing 55 (1): $10-25$.

Packard, G., A.D. Gershoff, and D.B. Wooten. 2016. When boastful word of mouth helps versus hurts social perceptions and persuasion. Journal of Consumer Research 43 (1): 26-43.

Patsiaouras, G., and J.A. Fitchett. 2012. The evolution of conspicuous consumption. Journal of Historical Research in Marketing 4 (1): 154-176.

Pickett, C.L., and M.B. Brewer. 2001. Assimilation and differentiation needs as motivational determinants of perceived in-group and out-group homogeneity. Journal of Experimental Social Psychology 37 (4): 341-348.

Price, L.L., and E.J. Arnould. 1999. Commercial friendships: Service provider-client relationships in context. Journal of Marketing 63 (4): 38-56.

Radighieri, J.P., and M. Mulder. 2014. The impact of source effects and message valence on word of mouth retransmission. International Journal of Market Research 56 (2): 59-73.

Rhee, E., J.S. Uleman, and H.K. Lee. 1996. Variations in collectivism and individualism by ingroup and culture: Confirmatory factor analysis. Journal of Personality and Social Psychology 71 (5): 1037-1054.

Rogers, E.M. 1983. Diffusion of innovations, 3rd ed. New York: The Free Press.

Roy, S., A. Guha, A. Biswas, and D. Grewal. 2019. Celebrity endorsements in emerging markets: Align endorsers with brands or with consumers? Journal of International Business Studies 50 (3): 295-317.

Ryu, G., and L. Feick. 2007. A penny for your thoughts: Referral reward programs and referral likelihood. Journal of Marketing 71 (1): 84-94.

Ryu, G., and J.K. Han. 2009. Word-of-mouth transmission in settings with multiple opinions: The impact of other opinions on WOM likelihood and valence. Journal of Consumer Psychology 19 (3): 403-415.

Siems, F., and R. Gerstandl. 2011. Word-of-mouth communication of prices: Theory, implications, and results: An empirical analysis in the airline industry. International Journal of Business Strategy 11: 17-34.

Sivakumar, K. 2014. National culture and inter-tier price competition. Journal of Product \& Brand Management 23 (2): 131-138.

Slama, M., R. Nataraajan, and T.G. Williams. 2015. Market mavens and the relationship between smart buying and information provision: An exploratory study. In Proceedings of the 1992 Academy of Marketing Science (AMS) Annual Conference, pp. 90-93. Cham: Springer. 
Soares, A.M., M. Farhangmehr, and A. Shoham. 2007. Hofstede's dimensions of culture in international marketing studies. Journal of Business Research 60 (3): 277-284.

Søndergaard, M. 1994. Research note: Hofstede's consequences: A study of reviews, citations and replications. Organization Studies 15 (3): 447-456.

Steenkamp, J.B., F. ter Hofstede, and M. Wedel. 1999. A crossnational investigation into the individual and cultural antecedents of consumer innovativeness. Journal of Marketing 63 (2): 55-69.

Stephen, A.T., and D.R. Lehmann. 2009. Why do people transmit word-of-mouth? The effects of recipient and relationship characteristics on transmission behaviors. Available at SSRN 1150996: 4.

Taras, V., B.L. Kirkman, and P. Steel. 2010. Examining the impact of culture's consequences: A three-decade, multilevel, meta-analytic review of Hofstede's cultural value dimensions. Journal of Applied Psychology 95 (3): 405-439.

Trusov, M., R.E. Bucklin, and K. Pauwels. 2009. Effects of word-ofmouth versus traditional marketing: Findings from an internet social networking site. Journal of Marketing 73 (5): 90-102.

Tsui, J., and C. Windsor. 2001. Some cross-cultural evidence on ethical reasoning. Journal of Business Ethics 31 (2): 143-150.

Van Parys, J., and E. Ash. 2018. Sequential decision-making with group identity. Journal of Economic Psychology 69: 1-18.

Wicken, G., and R. Asquith. 2008. Turning the amplification up to 11. International Journal of Market Research 50 (6): 777-795.

Yang, K.S. 1981. Social orientation and individual modernity among Chinese students in Taiwan. Journal of Social Psychology 113 (2): 159-170.
Yoo, B., N. Donthu, and S. Lee. 2000. An examination of selected marketing mix elements and brand equity. Journal of the Academy of Marketing Science 28 (2): 195-211.

Zhang, X., S. Li, and R.R. Burke. 2018. Modeling the effects of dynamic group influence on shopper zone choice, purchase conversion, and spending. Journal of the Academy of Marketing Science 46 (6): 1089-1107.

Zhang, J., and M.R. Nelson. 2016. The effects of vertical individualism on status consumer orientations and behaviors. Psychology \& Marketing 33 (5): 318-330.

Zhu, F., and X. Zhang. 2010. Impact of online consumer reviews on sales: The moderating role of product and consumer characteristics. Journal of Marketing 74 (2): 133-148.

Publisher's Note Springer Nature remains neutral with regard to jurisdictional claims in published maps and institutional affiliations.

Sebastian Schneider is an adjunct professor and research associate at Johannes Gutenberg University's school of management and economics. Besides his Doctor of Management and Economics (Dr. rer. pol.), he holds a Master of Science in Management (M.Sc.) and a Magister Artium in Business Administration and Geography (M. A.). His professional experience in Germany and the United States includes market research and analyst work in travel, tourism, and small business promotion. 